\title{
Iron in Infection and Immunity
}

\author{
James E. Cassat, M.D., Ph.D. ${ }^{1}$ and Eric P. Skaar, Ph.D., M.P.H. ${ }^{2,}$ \\ ${ }^{1}$ Department of Pediatrics, Division of Pediatric Infectious Diseases, Vanderbilt University Medical \\ Center, Nashville, TN, 37237, USA \\ ${ }^{2}$ Department of Pathology, Microbiology, \& Immunology, Vanderbilt University School of \\ Medicine, Nashville, TN, 37232, USA
}

\begin{abstract}
Iron is an essential nutrient for both humans and pathogenic microbes. Because of its ability to exist in one of two oxidation states, iron is an ideal redox catalyst for diverse cellular processes including respiration and DNA replication. However, the redox potential of iron also contributes to its toxicity, thus iron concentration and distribution must be carefully controlled. Given the absolute requirement for iron by virtually all human pathogens, an important facet of the innate immune system is to limit iron availability to invading microbes in a process termed nutritional immunity. Successful human pathogens must therefore possess mechanisms to circumvent nutritional immunity in order to cause disease. In this review, we discuss regulation of iron metabolism in the setting of infection and delineate strategies used by human pathogens to overcome iron-withholding defenses.
\end{abstract}

\section{Mechanisms of iron homeostasis in human health and disease}

\section{la. Human iron homeostasis}

Iron is an essential nutrient for humans, with critical functions in many cellular processes. The biologic utility of iron resides in its ability to cycle between two oxidation states: ferrous $\left(\mathrm{Fe}^{2+}\right)$ or ferric $\left(\mathrm{Fe}^{3+}\right)$. Iron can thus serve as a redox catalyst, accepting or donating electrons. However, the redox potential of iron also generates cellular toxicity under conditions of iron overload. Reactive oxygen intermediates are generated during the course of normal cellular homeostasis. In the presence of such reactive oxygen species, iron can catalyze the Fenton reaction to generate hydroxyl radicals that damage lipids, DNA, and protein. It is therefore critical to regulate both the quantity and subcellular location of iron.

Iron absorption occurs in the proximal duodenum, with the amount of iron absorbed being dependent on the sufficiency of iron stores. Human iron metabolism is remarkably efficient, as only $0.5-1 \mathrm{mg}$ of the approximately $4-5 \mathrm{~g}$ of total body iron in adults is lost daily (Nathan et al., 2003). Upon arrival in the duodenum, ferric iron is reduced by ferric reductases present in the apical brush border of enterocytes (Figure 1A). Ferrous iron is then transported into the enterocyte by the divalent metal ion transporter DMT1 (also known as Nramp2). After transport into the enterocyte, ferrous iron can be stored, used for cellular processes, or exit the cell through the basolateral membrane transporter ferroportin (FPN1)

(C) 2013 Elsevier Inc. All rights reserved.

*Address for correspondence: Eric P. Skaar, eric.skaar@vanderbilt.edu, Phone: 615-343-0002, Fax: 615-343-7392.

Publisher's Disclaimer: This is a PDF file of an unedited manuscript that has been accepted for publication. As a service to our customers we are providing this early version of the manuscript. The manuscript will undergo copyediting, typesetting, and review of the resulting proof before it is published in its final citable form. Please note that during the production process errors may be discovered which could affect the content, and all legal disclaimers that apply to the journal pertain. 
(Abboud and Haile, 2000; Donovan et al., 2000; McKie et al., 2000). In healthy individuals, nearly all iron released into plasma is bound to transferrin, limiting iron-catalyzed free radical production and facilitating transport to target cells. Delivery of iron-loaded transferrin into target cells is accomplished by receptor-mediated endocytosis (Figure 1B). Endosomal acidification facilitates release of iron, and the apotransferrin - transferrin receptor complex is recycled to the cell surface. Ferric iron released from transferrin is reduced in the endosome by the ferrireductase STEAP3, and subsequently transported into the cytoplasm by DMT1 (Nathan et al., 2003). From this point, the fate of iron depends on cellular needs. Iron can be used in the biosynthesis of heme, a tetrapyrrole molecule serving both as a prosthetic group for metalloenzymes and as the oxygen-binding moiety of hemoglobin. Alternatively, iron can be incorporated into iron-sulfur clusters, redox cofactors used in metalloenzymes. Finally, iron can be stored intracellularly as ferritin, a spherical heteropolymer capable of storing greater than 4000 iron atoms.

The majority of human iron is found in erythrocytes, complexed to heme moieties in hemoglobin. Four molecules of heme are bound to each hemoglobin tetramer. Each erythrocyte can contain as many as 280 million molecules of hemoglobin, resulting in an iron capacity of over 1 billion atoms per cell (Nathan et al., 2003). Primary functions of hemoglobin include delivery of oxygen to tissues, removal of carbon dioxide and carbon monoxide from the body, and regulation of vascular tone through nitric oxide binding. Hemoglobin in senescent erythrocytes is meticulously recycled by macrophages in the reticuloendothelial system (Figure 1C). Heme oxygenase (HO-1) releases iron and carbon monoxide from the protoporphyrin ring, resulting in the production of biliverdin and shuttling of iron back to the transferrin or ferritin pools.

Iron metabolism is tightly regulated to avoid both cellular damage associated with iron overload, and anemia associated with iron deficiency. Iron levels are controlled by iron regulatory proteins (IRP1 and IRP2), which bind to iron response elements (IRE) in the mRNA encoding factors associated with iron metabolism. In addition to IRP-mediated regulation of cellular iron levels, iron metabolism is regulated systemically. Hepcidin, a peptide hormone produced in the liver, post-translationally regulates ferroportin and thus controls entry of iron into the plasma after enterocyte absorption. Increases in total body iron stores trigger the production of hepcidin, which subsequently induces the internalization and degradation of ferroportin (Nemeth et al., 2004). As ferroportin is present on the surface of macrophages, hepcidin also decreases iron export after recycling by the reticuloendothelial system.

\section{Ib. Iron limitation as an innate immune defense}

In addition to mitigating toxicity associated with hypo- or hyperferremia, regulation of iron distribution serves as an innate immune mechanism against invading pathogens. Even in the absence of infection, several facets of human iron metabolism ensure that iron is scarcely accessible to pathogenic microorganisms. First, the majority of iron in humans is sequestered intracellularly, complexed within hemoglobin inside erythrocytes. Some pathogens have therefore evolved mechanisms to liberate hemoglobin by lysing erythrocytes to ultimately extract iron from heme. However, hemolytic pathogens must subsequently compete with haptoglobin and hemopexin, host glycoproteins that scavenge liberated hemoglobin and heme, respectively (Figure 1D). A second factor limiting the availability of iron to invading pathogens is the paucity of free extracellular iron. Extracellular iron is bound with high affinity by transferrin, which in healthy individuals is typically less than $50 \%$ saturated with iron. When transferrin binding capacity is exceeded, iron can also be chelated with lower affinity by a number of molecules in plasma including albumin, citrate, and amino acids (Nathan et al., 2003). 
During infection, additional fortification of iron-withholding defense occurs (F igure). The hypoferremia of infection was documented in seminal studies by 2 Cartwright et al. in the 1940s, who noted a precipitous drop in plasma iron levels upon intramuscular inoculation of canines with Staphylococcus aureus. A similar hypoferremic response was noted upon intravenous injection with sterile turpentine, suggesting that inflammation, rather than a specific microbial product was responsible for declining plasma iron levels (Cartwright et al., 1946). Since these initial observations, much has been learned regarding the importance of iron withholding to the outcome of the host-pathogen interactions.

Hepcidin is a major orchestrator of the hypoferremic response to infection. In fact, hepcidin was initially characterized as an antimicrobial peptide in human urine and blood ultrafiltrate (Krause et al., 2000; Park et al., 2001). Hepcidin release from the liver is stimulated by proinflammatory cytokines, TLR activation, and induction of the endoplasmic reticulum unfolded protein response (Figure 2A) (Drakesmith and Prentice, 2012). In addition to hepcidin production in the liver, neutrophils and macrophages synthesize hepcidin in response to infectious agents, allowing for modulation of iron availability at the infectious focus (Peyssonnaux et al., 2006).

The hypoferremic response to infection is also mediated by hepcidin-independent mechanisms. Cytokines such as interferon-gamma, tumor necrosis factor-alpha, IL-1, and IL-6 modulate iron metabolism to further strengthen iron-withholding defenses (Figure 2B C) (Nairz et al., 2010; Weiss, 2005).

In addition to systemic induction of hypoferremia through hepcidin-dependent and independent mechanisms, innate immune effectors further sequester iron locally at infectious foci (Figure 2C-D). Lactoferrin is a host glycoprotein that, like transferrin, binds free iron with high affinity. Mucosal secretions contain high concentrations of lactoferrin, comprising a constitutive mechanism for iron limitation at mucosal surfaces. Additionally, the specific ("secondary") granules of neutrophils contain lactoferrin, which is released at infectious sites in response to cytokines (Masson et al., 1969). Moreover, unlike transferrin, lactoferrin maintains iron-binding capacity at low $\mathrm{pH}$ and therefore may be a more effective scavenger in acidotic infectious foci (Baker and Baker, 2012). Activation of phagocytes at the site of infection also limits iron availability to intracellular pathogens (Figure 2C). Pattern recognition receptor binding and pro-inflammatory cytokines decrease the expression of transferrin receptors on the surface of phagocytes, while enhancing expression of the intracellular iron transporter, Nramp1. Nramp1 (natural resistance associated macrophage protein-1) is a divalent metal ion transporter that has been proposed to reduce iron content in early endosomes, thereby limiting availability to intracellular pathogens in this compartment (Jabado et al., 2000; Vidal et al., 1995). However, Nramp1 has also been suggested to facilitate the delivery of iron into late endosomes and lysosomes, harnessing the toxic properties of iron to control microbial growth (Zwilling et al., 1999).

Polymorphisms in Nramp1 have been found to correlate with enhanced human susceptibility to Mycobacterium tuberculosis (Mtb), suggesting that intraphagosomal iron limitation might be an important innate immune defense (van Crevel et al., 2009).

\section{Ic. Disorders of iron homeostasis that enhance susceptibility to infectious diseases}

The importance of strict regulation of iron metabolism is underscored by the pathologic consequences of iron overload syndromes. Individuals suffering from iron overload not only experience cellular damage from adverse redox chemistry of free iron, but also are at enhanced risk of infection. Iron overload may result from mutations in iron metabolism genes, such as in hereditary hemochromatosis. Alternatively, iron overload may be secondary to refractory anemias or caused by chronic transfusions. 
Hereditary hemochromatosis is a heterogeneous disease caused by at least five different types of mutations in genes related to iron metabolism. Patients suffering from hemochromatosis develop iron deposits in organs such as the heart and liver, leading to oxidative damage, liver dysfunction and cardiomyopathy. Hemochromatosis is treated preferentially with serial phlebotomy, or when phlebotomy is not possible, iron chelators. Iron overload can also occur secondary to refractory anemias, chronic transfusions, or chronic liver disease. "Iron-loading" refractory anemias such as beta thalassemia and sideroblastic anemia are characterized by erythroid hyperplasia, ineffective erythropoiesis, and excessive iron absorption. Such patients experience many of the iron-related organ pathologies observed in patients with hemochromatosis.

Regardless of the underlying etiology, the availability of iron to invading pathogens is enhanced during iron overload, and such individuals therefore have an increased susceptibility to a variety of infectious diseases. Patients with iron overload from hemochromatosis and thalassemia are more susceptible to infection with Yersinia spp., Listeria monocytogenes, and Vibrio vulnificus, among others (Long et al., 2003).

\section{Iron acquisition by pathogenic microbes}

\section{Ila. Iron acquisition by predominantly extracellular bacterial pathogens}

Iron is an essential nutrient for nearly all bacterial species that infect humans. Bacterial pathogens must therefore possess mechanisms to overcome iron-withholding defenses in order to successfully colonize humans. The specific strategies used to accomplish this goal depend considerably on the host niche, and whether the microbe adopts predominately an intracellular or extracellular lifestyle. Bacterial pathogens also differ with respect to the preferred iron source, whether free, chelated to host compounds, or associated with heme and hemoglobin. Nevertheless, bacterial pathogens employ one or a combination of five primary mechanisms to satisfy the requirement for nutrient iron (Figure 3). One mechanism, used by Borrelia burgdorferi, is to utilize manganese instead of iron in metalloenzymes, thereby eliminating the need for iron acquisition systems (Posey and Gherardini, 2000). Other mechanisms for acquisition of host iron include the production of siderophores, heme acquisition systems, transferrin or lactoferrin receptors, and ferric or ferrous iron transporters. In the following sections, model bacterial pathogens are used as examples to further delineate strategies for host iron acquisition.

Siderophores-Produced by a wide range of Gram-positive and Gram-negative human pathogens, siderophores are small ferric iron chelators capable of binding iron with association constants that can exceed $10^{50}$ (Bullen JJ, 1999). Siderophores can therefore effectively outcompete host transferrin, which binds iron with an association constant of approximately $10^{36}$. Because of their incredible iron-binding affinity, siderophores are used clinically in treatment of iron overload syndromes (e.g. desferrioxamine B from Streptomyces pilosus). They are synthesized under conditions of low iron availability and secreted into the extracellular environment, where they bind ferric iron and facilitate its use by microbial cells (Figure 3A-3B). Once inside the cell, siderophore-bound iron can be released through enzymatic degradation of the siderophore or via reduction of ferric to ferrous iron which destabilizes the iron-siderophore complex. One advantage of siderophore-based strategies for iron acquisition is the potential for uptake of xenosiderophores, or iron-chelating molecules not produced by the microbe. For example, $V$. vulnificus, $S$. aureus, and $Y$. enterocolitica, among others, can utilize desferrioxamine B as an iron source. Chelation therapy with desferrioxamine may therefore increase the risk of infection in patients with iron overload (Kim et al., 2007). 
Bacterial siderophore production is typically regulated in an iron-dependent manner by either the ferric uptake regulator (Fur) or the diphtheria toxin regulator (DtxR). Both Fur and DtxR repress transcription of target genes in the presence of iron. In iron-deplete environments, transcriptional repression is relieved, and synthesis of iron homeostatic systems can proceed. The production of siderophores contributes to the virulence of a variety of pathogens, including $S$. aureus, Escherichia coli, Legionella pneumophila, and Bacillus anthracis, among others (Cassat and Skaar, 2012). Understanding the mechanisms by which siderophores disrupt host biologic processes is an active area of investigation. Pyoverdin, one of two siderophores produced by Pseudomonas aeruginosa, elicits host cell death in Caenorhabditis elegans by induction of a hypoxic response dependent on the ironresponsive transcription factor HIF-1 (Kirienko et al., 2013). Given the ability of siderophores to hijack host iron homeostasis, it is not surprising that the human innate immune system has evolved mechanisms to counteract siderophore-mediated iron acquisition. Siderocalin, also known as lipocalin-2 (Lcn2) or neutrophil gelatinaseassociated lipocalin, is expressed during the acute phase response to infection and sequesters siderophores (Figure 2D). Siderocalin was initially characterized by its ability to bind the $E$. coli siderophore enterochelin, inhibiting its growth. Accordingly, siderocalin-deficient mice display an enhanced susceptibility to E. coli septicemia (Flo et al., 2004). Because siderocalin effectively neutralizes siderophore-mediated iron uptake, pathogens have evolved mechanisms to circumvent this host defense. One such mechanism is the production of "stealth siderophores", which have structural modifications that preclude siderocalin binding. For instance, this strategy is used by B. anthracis and Salmonella Typhimurium, both of which produce modified siderophores that are not bound by siderocalin (Abergel et al., 2006; Raffatellu et al., 2009). In this way, iron-dependent pathogens can maintain a competitive advantage in the struggle for host iron.

Heme uptake systems-As most iron in humans is contained within hemoglobin, many pathogens have developed mechanisms to liberate hemoglobin from erythrocytes and utilize heme as a nutrient. However, the redox capacity of heme also has the potential to incite cellular toxicity if levels are not appropriately regulated. Bacterial pathogens must therefore carefully balance heme acquisition with heme detoxification. The requirement for heme may be satisfied through endogenous heme production, exogenous heme acquisition, or some combination of these activities. Some bacterial pathogens, such as Haemophilus influenzae, are incapable of endogenous heme biosynthesis and therefore depend exclusively on exogenous heme acquisition. Two major classes of bacterial heme acquisition systems exist: direct heme uptake systems and hemophore-dependent systems (Anzaldi and Skaar, 2010). All heme acquisition systems contain cell surface receptors that bind heme or hemoproteins, machinery to shuttle heme across the cell wall and membrane(s), and cytoplasmic components to liberate iron from heme or shuttle heme intact to heme-containing enzymes.

Gram-positive bacteria typically encode direct heme uptake systems, although a hemophoredependent uptake system has been characterized in B. anthracis (Figure 3A) (Maresso et al., 2008). The $S$. aureus iron-regulated surface determinant (Isd) system is the paradigm for direct heme uptake in Gram-positive bacteria. Although it encodes other iron acquisition pathways, the preferred iron source for $S$. aureus is heme (Skaar et al., 2004b). The Isd system is encoded by ten genes in five operons: isd $A$, isdB, isdCDEFsrtBisdG, isd $H$, and isdI (Hammer and Skaar, 2011; Mazmanian et al., 2003; Mazmanian et al., 2002). IsdB and IsdH encode cell surface receptors that bind hemoglobin and hemoglobin-haptoglobin, respectively (Dryla et al., 2003; Torres et al., 2006). Heme is then shuttled through the cell wall by IsdA and IsdC prior to transport into the cytoplasm by the ABC-type transporter IsdDEF (Grigg et al., 2007). Upon entering the cytoplasm, heme can be shuttled intact to the cell membrane, or degraded by the heme oxygenases IsdG and IsdI to release iron (Reniere and Skaar, 2008; Skaar et al., 2004a). Unlike mammalian heme oxygenases that degrade 
heme to iron, biliverdin, and carbon monoxide, staphylococcal heme oxygenases degrade heme to iron and the novel chromophore staphylobilin (Reniere et al., 2010). Acquisition of heme by the Isd system is critical for $S$. aureus pathogenesis (Cassat and Skaar, 2012). Of note, $S$. aureus the Isd system has evolved to utilize human hemoglobin preferentially over hemoglobin from other species. Accordingly, transgenic mice expressing human hemoglobin alleles are more susceptible to $S$. aureus infection (Pishchany et al., 2010). Homologues of the Isd system exist in other staphylococcal species and a variety of Grampositive pathogens (Cabanes et al., 2002; Haley et al., 2011; Skaar et al., 2006; Zapotoczna et al., 2012).

Gram-negative organisms can acquire heme via direct uptake systems, hemophore-mediated systems, or both (Figure 3B). P. aeruginosa expresses both a direct uptake system and hemophore-mediated system for heme acquisition. The $P$. aeruginosa direct heme uptake system is encoded by a Fur-regulated operon, where phuR encodes an outer membrane heme receptor, phuT encodes a periplasmic heme transport protein, phuUVW encodes a cell membrane- associated ABC transporter, and phuS encodes a cytoplasmic heme-binding protein (Tong and Guo, 2009). Heme transport across the Gram-negative outer membrane is energy-dependent and requires the TonB/ExbB/ExbD system. TonB spans the periplasm, harnessing energy from the proton motive force to enable substrate delivery from outer membrane receptors. The TonB/ExbB/ExbD system is also involved in transport of siderophore-iron complexes. Once heme is delivered into the cytoplasm of Gram-negative organisms, it can be degraded by heme oxygenases to release iron. Similar direct heme uptake systems are expressed by a number of Gram-negative pathogens (Anzaldi and Skaar, 2010).

$P$. aeruginosa also expresses a hemophore-mediated heme uptake system. HasAp is a homolog of the Serratia marcesens $19 \mathrm{kDa}$ extracellular heme-binding protein HasA (Letoffe et al., 1998). HasA is secreted by the Type I secretion pathway, captures extracellular heme from host hemoproteins, and then interacts with a TonB-dependent hemophore receptor HasR (Cescau et al., 2007). Homologs of the Has system are present in $P$. fluorescens, $Y$. pestis, and $Y$. enterocolitica (Tong and Guo, 2009).

Transferrin/Lactoferrin receptors-Siderophores allow bacterial pathogens to compete with the high-affinity iron-binding host glycoproteins transferrin and lactoferrin. However, some pathogens have evolved mechanisms for direct acquisition of transferrin or lactoferrinbound iron (Figure 3B). Neisseria meningitidis expresses both transferrin and lactoferrin uptake systems. Consistent with its role as an obligate human pathogen, $N$. meningitidis preferentially utilizes human transferrin (Schryvers and Morris, 1988). The transferrin receptor consists of two proteins, TbpA and TbpB, both expressed under iron-limiting conditions and subject to regulation by Fur. Similarly, the lactoferrin-binding receptor consists of LbpA (formerly IroA) and LbpB, and is also Fur-regulated. Utilization of transferrin and lactoferrin as an iron source requires the TonB/ExbB/ExbD system. The crystal structure of the TbpA-transferrin complex suggests a mechanism whereby TonB facilitates a conformational change in TbpA, allowing for release of ferric iron from transferrin and subsequent transport into the periplasm (Noinaj et al., 2012). Transferrin binding is important for the virulence of Neisseria spp., as tbp mutants are avirulent in a human model of infection (Cornelissen et al., 1998).

\section{Ilb. Iron acquisition by intracellular bacterial pathogens}

Bacterial pathogens that adopt a predominantly intracellular lifestyle during infection may encounter cellular compartments of varying iron content. Macrophages, a common niche for intracellular replication, serve a key role in iron homeostasis through recycling of host iron- 
containing compounds. Intracellular pathogens have therefore adopted distinct strategies to acquire iron earmarked for storage, host cellular processes, or recycling (Figure 3C) (Nairz et al., 2010).

Mtb is a facultatively intracellular pathogen infecting approximately one-third of the world's population. It is transmitted via aerosolized droplets and initially colonizes the terminal airspaces where it is phagocytosed by alveolar macrophages. Inside the macrophage, Mtb disrupts phagolysosomal maturation, an iron-dependent process critical for pathogen survival (Olakanmi et al., 2000). Intracellular mycobacteria therefore utilize several mechanisms to obtain host iron. Similar to predominantly extracellular pathogens, pathogenic mycobacteria express siderophores known as mycobactins, the biosynthesis of which has been elegantly investigated using lipidomics profiling (Madigan et al., 2012). Disruption of mycobactin synthesis impairs growth within macrophages, suggesting that siderophore production is an important iron acquisition strategy for Mtb (De Voss et al., 2000). Radiolabeling studies demonstrated that Mtb acquires iron either from transferrin as it cycles through the endocytic pathway, or from cytoplasmic iron stores (Olakanmi et al., 2002). Acquisition of cytoplasmic iron is facilitated by the ability of mycobactins to diffuse out of the phagosome, chelate iron, and reassociate with phagosomes via lipid droplets (Luo et al., 2005). This strategy essentially increases the intracellular pool of host iron that can be accessed by Mtb. Interestingly, patients with hereditary hemochromatosis have reduced intracellular iron levels, and thus monocytes derived from such individuals are less permissive to Mtb replication (Olakanmi et al., 2002). Therefore, although hereditary hemochromatosis generally enhances susceptibility to infectious disease, certain subtypes may confer a selective advantage against intracellular pathogens. Mtb also employs a heme/ hemoglobin uptake system to obtain host iron, although the precise mechanisms of heme uptake have yet to be elucidated (Tullius et al., 2011).

To counteract Mtb iron acquisition, IFN-gamma activates macrophages to downregulate cell-surface transferrin receptors, effectively decreasing iron concentrations in late endosomes (Olakanmi et al., 2002). Additionally, ferroportin rapidly localizes to Mtbinfected phagolysosomes, resulting in iron efflux from this cellular compartment. Mycobacteria circumvent these iron-withholding defenses by directly modulating ferroportin expression (Van Zandt et al., 2008).

\section{Ilc. Iron detoxification strategies in bacterial pathogens}

The potent redox capability of iron requires that bacterial pathogens carefully regulate iron concentration and distribution. Pathogenic microbes use mechanisms analogous to those in human iron homeostasis to maintain a proper distribution of iron: storage, regulation of uptake, and regulation of efflux. As discussed above, iron acquisition is regulated in accordance with environmental cues by iron-dependent regulators such as Fur and DtxR. However, acquisition must also be carefully coordinated with storage and efflux to ensure iron homeostasis.

Excess iron can be stored in iron storage proteins, creating an intracellular surplus of iron that can be utilized in iron-deplete conditions, while also limiting the potential for ironmediated free radical formation. Bacterial pathogens store iron in one of three types of proteins: ferritin, bacterioferritins, and Dps proteins. Ferritins and bacterioferritins have a similar structure, with each molecule consisting of 24 subunits assembled into a sphere around an iron-storage cavity. Bacterioferritins also contain up to 12 heme molecules per $24 \mathrm{mer}$. In contrast, Dps proteins are spherical $12 \mathrm{mers}$, and accommodate fewer iron atoms per molecule (Andrews et al., 2003). Ferritins and bacterioferritins enhance growth of ironstarved pathogens such as E. coli, Campylobacter jejuni, and Helicobacter, pylori protect against redox stress, and contribute to survival within the host. For example, disruption of 
Mtb ferritin biosynthesis limits resistance to oxidative stress, enhances susceptibility to antibiotics, and decreases bacterial survival in a chronic infection model (Pandey and Rodriguez, 2012). Similarly, both Dps and the ferritin FtnB are required for full virulence of $S$. Typhimurium (Halsey et al., 2004; Velayudhan et al., 2007).

An alternative strategy to alleviate iron toxicity is the export of iron-containing compounds or their toxic metabolites. A model system for this strategy is provided by the $S$. aureus heme-regulated transporter (Hrt). The existence of a heme detoxification system in $S$. aureus was suggested by the observation that staphylococci exposed to subinhibitory concentrations of heme can subsequently resist heme toxicity at supraphysiologic concentrations (Torres et al., 2007). HrtAB was identified as an ABC-type transporter that dramatically increases abundance following heme exposure (Friedman et al., 2006). Inactivation of the genes encoding the HrtAB transporter leads to impairment of growth in media containing high concentrations of heme (Stauff et al., 2008). Subsequent analyses identified genes encoding a two-component regulatory system adjacent to hrt $A B$. The proteins encoded by these genes, termed HssR and HssS for heme-sensor system regulator and sensor, are required for the adaptive response to heme toxicity (Stauff et al., 2007). HssRS senses heme exposure, increasing expression of hrtAB, which results in alleviation of heme toxicity. The exact molecule that is sensed by HssS remains to be elucidated. $S$. aureus heme toxicity occurs in part due to membrane-associated oxidative damage, which is potentiated by the electron carrier menaquinone (Wakeman et al., 2012). Although the molecule(s) exported by $S$. aureus $\mathrm{HrtAB}$ to alleviate heme toxicity is unknown, the Lactococcus lactis HrtAB transporter specifically effluxes heme (Lechardeur et al., 2012). Orthologs of the HrtAB system have been identified in B. anthracis, L. monocytogenes, Enterococcus faecalis, and Streptococcus agalactiae (Anzaldi and Skaar, 2010).

\section{Iron acquisition and storage by pathogenic fungi}

Pathogenic fungi, like bacterial pathogens, must obtain iron from host tissues and regulate iron homeostasis to avoid toxicity. Furthermore, iron serves as an important signal for some fungi during the transition from a commensal lifestyle to that of an invasive pathogen (Chen et al., 2011). In general, three mechanisms exist for iron acquisition in fungi: reductive uptake, siderophore-mediated uptake, and heme acquisition (Howard, 1999). As in bacteria, these mechanisms are not necessarily mutually exclusive.

A primary fungal iron acquisition strategy is reductive iron uptake. S. cerevisiae and opportunistic fungal pathogens such as Candida albicans and Cryptococcus neoformans possess cell-surface ferric reductases which are coupled to iron transporters. Reduction of ferric to ferrous iron enables removal from host chelating molecules, and facilitates transport into the fungal cell. Both $C$. albicans and $C$. neoformans require reductive iron uptake for full virulence in animal infection models (Nevitt, 2011). C. albicans is also capable of exploiting host ferritin as an iron source using reductive uptake. In addition to roles in hyphal formation, adhesion, and invasion of host cells, the candidal protein Als3 serves as a ferritin receptor, demonstrating that iron acquisition components may serve multiple roles in virulence (Almeida et al., 2008).

Similar to bacterial pathogens, a variety of pathogenic fungi produce siderophores, including the agents of endemic mycoses (Histoplasma capsulatum and Blastomyces dermatitidis), zygomycetic organisms (Rhizopus spp.), and other invasive molds (Aspergillus spp.) (Howard, 1999). However, unlike bacterial pathogens, fungi can also produce intracellular siderophores for distribution and storage of iron. A. fumigatus, an important cause of invasive disease in immunocompromised patients, produces two intracellular siderophores: hyphal ferricrocin and conidial hydroxyferricrocin (Schrettl and Haas, 2011). By 
maintaining proper intracellular iron distribution, these compounds promote germination and resistance to oxidative stress, and are required for full virulence in a mouse model of invasive infection (Schrettl et al., 2007).

A third mechanism of fungal iron acquisition is the uptake of heme. The growth of $C$. neoformans, $C$. albicans, and $H$. capsulatum in iron-deplete media is enhanced upon addition of heme or hemoglobin (Foster, 2002; Hu et al., 2013; Weissman et al., 2002). Unlike bacterial heme uptake systems, hemoglobin uptake by $C$. albicans appears to utilize a novel endocytosis-mediated mechanism (Weissman et al., 2008). The importance of heme uptake systems for fungal pathogenesis remains to be tested.

\section{Iron homeostasis in human parasites}

Parasitic infections are a substantial source of morbidity and mortality worldwide. The link between endoparasitic infection and human iron homeostasis is, in some cases, quite direct. Human hookworms infect greater than 700 million people worldwide and are a leading cause of iron deficiency anemia in the developing world (Long et al., 2003). Hookworms feed on human blood, using a hemolysin to lyse erythrocytes and anticoagulants to resist clotting. Ingested hemoglobin is subsequently digested by a cascade of proteases before use as a nutrient source (Williamson et al., 2004). In other parasitic infections, the connection between pathogen and host iron homeostasis is less direct, but many human parasites rely on host iron and iron-containing compounds to cause disease.

Up to two-thirds of the world's population are exposed to malaria annually, of which over 240 million will contract the disease and up to 2 million will die (Long et al., 2003). Malaria is caused by one of five species of Plasmodium, with $P$. falciparum being the most virulent. The Plasmodium lifecycle includes an intra-erythrocytic stage, creating a unique opportunity to manipulate the richest reservoir of iron in the host. Similar to human hookworms, $P$. falciparum also uses host hemoglobin as a nutrient source, and has evolved a distinct mechanism for protecting against iron toxicity. Hemoglobin is ingested by intra-erythrocytic Plasmodia, transported to a specialized organelle known as the food vacuole, and degraded to nutrient amino acids by a proteolytic cascade. However, digestion of hemoglobin also releases heme, which is toxic at elevated concentrations. To limit toxicity, Plasmodia sequester heme into a pigment known as hemozoin, which accumulates in the organs of infected individuals. After erythrocyte rupture, hemozoin is released into the circulation and ingested by phagocytes, where it has profound immunomodulatory effects (Hanscheid et al., 2007; Shio et al., 2010). The importance of hemozoin-mediated heme detoxification in $P$. falciparum is illustrated by the clinical efficacy of quinoline drugs, which inhibit hemozoin synthesis.

The pathogenesis of malaria also illustrates the intricate relationship between host iron metabolism and the innate immune system. Detoxification of iron and iron-containing compounds serves a cytoprotective role during infection by limiting the tissue damage associated with iron overload. For example, induction of ferritin $\mathrm{H}$ chain $(\mathrm{FtH})$ expression in host tissues confers tolerance to malaria through FtH-mediated iron sequestration, ferroxidase activity, and inhibition of oxidative damage by modulation of JNK signaling (Gozzelino et al., 2012). However, induction of cytoprotective iron-detoxification strategies may paradoxically limit innate immunity. Non-Typhoid Salmonella (NTS) bacteremia is a common and often fatal complication of malaria. Hemolysis during malaria induces the expression of HO-1, which protects host cells by detoxifying heme. Accordingly, HO-1 induction limits the morbidity of experimental malaria (Seixas et al., 2009). However, HO-1 induction during experimental malaria impairs resistance to NTS by limiting the oxidative burst of granulocytes. (Cunnington et al., 2012). Thus, induction of host iron detoxification 
systems by one pathogen may alter susceptibility to another. Yet other host ironsequestering responses may fortify innate immunity. The siderophore-sequestering molecule Lcn2 is abundantly produced during malaria. Lcn2 plays a critical role in control of parasitemia through suppression of reticulocytosis, enhancement of macrophage function, and modulation of adaptive immune responses (Zhao et al., 2012).

\section{Targeting microbial iron homeostasis for the treatment of infectious diseases}

The vast majority of human pathogens require iron to sustain growth and colonize humans. Targeting microbial iron acquisition is therefore a promising therapeutic strategy. Both antimicrobial compounds and vaccines targeting pathogen iron homeostasis are currently being developed.

Antimicrobial compounds targeting pathogen iron homeostasis can be broadly divided into two categories: compounds that target the biosynthesis of iron acquisition determinants and "Trojan horse" compounds that exploit iron acquisition pathways for selective targeting of antibiotics. Of the former class, compounds that target siderophore production are the best characterized. One of the earliest antimicrobials used for treatment of tuberculosis, $p$ aminosalicylic acid (PAS), inhibits mycobactin biosynthesis (Ratledge and Brown, 1972). Subsequently, a large number of inhibitors of siderophore biosynthesis have been developed. A second iron-associated strategy for the development of new antimicrobials is to covalently link siderophores to antibiotic compounds to create "sideromycins". Siderophore conjugation decreases the minimum inhibitory concentration of several antibiotics, including beta-lactams, vancomycin, and fluoroquinolones. The efficacy of select sideromycins has been evaluated in vivo. Albomycin, a sideromycin produced by Streptomyces spp., protects mice from $S$. pneumoniae and $Y$. enterocolitica systemic infection (Pramanik et al., 2007). Similarly, the synthetic siderophore-conjugated beta-lactam MC-1, is active against $P$. aeruginosa both in vitro and in vivo (McPherson et al., 2012).

A limited number of vaccines have been created to specifically target pathogen iron acquisition systems. A "reverse vaccinology" approach revealed that antibodies targeting IsdA and IsdB were protective against $S$. aureus infection (Stranger-Jones et al., 2006). Similarly, Alteri et al. used a large-scale vaccinology approach to identify candidate uropathogenic $E$. coli vaccine antigens and found that immunization with six outer membrane iron receptors protected against UTI (Alteri et al., 2009). In addition to targeting iron acquisition proteins, some efficacy has been achieved with vaccines targeting iron homeostasis in pathogens. The Na-APR-1 protease from human hookworm, Necator americanus, is essential for enzymatic activity to support blood feeding. Vaccination with a mutated form of Na-APR-1 significantly reduced parasite burden in experimentally-infected canines (Pearson et al., 2009).

\section{Concluding remarks}

In summary, human pathogens have evolved a plethora of mechanisms to obtain host iron. In response to infection, the innate immune system further strengthens iron-withholding defenses, ensuring that the host-pathogen interface remains an ever-evolving battleground for precious metal. Despite considerable efforts to define the host and microbial determinants of iron homeostasis during infection, several important questions remain to be answered. First, given that microbes often possess redundant mechanisms for iron acquisition, which microbial iron acquisition components are most critical for pathogenesis? Furthermore, which iron acquisition determinants are most capable of eliciting protective immunity when used for vaccine construction? The recent termination of human clinical 
trials for a $S$. aureus IsdB-containing vaccine highlights that protective immunity in animal models of infection may not always correlate to vaccine efficacy in humans (Daum and Spellberg, 2012). With respect to human iron homeostasis during infection and inflammation, is it possible to design therapies that manipulate the hepcidin axis to confer tolerance to infectious diseases? Such an approach may be beneficial in treating infectious diseases that are exacerbated by iron supplementation. Finally, the discovery of putative mammalian siderophores suggests that humans might use mechanisms analogous to microbes to maintain iron homeostasis (Bao et al., 2010; Devireddy et al., 2010). Whether mammalian siderophores have specific functions in nutritional immunity remains to be tested, but these compounds illustrate that an enhanced understanding of microbial iron acquisition strategies can further our understanding of human physiology.

\section{References}

Abboud S, Haile DJ. A novel mammalian iron-regulated protein involved in intracellular iron metabolism. The Journal of Biological Chemistry. 2000; 275:19906-19912. [PubMed: 10747949]

Abergel RJ, Wilson MK, Arceneaux JE, Hoette TM, Strong RK, Byers BR, Raymond KN. Anthrax pathogen evades the mammalian immune system through stealth siderophore production. Proceedings of the National Academy of Sciences of the United States of America. 2006; 103:18499-18503. [PubMed: 17132740]

Almeida RS, Brunke S, Albrecht A, Thewes S, Laue M, Edwards JE, Filler SG, Hube B. the hyphalassociated adhesin and invasin Als 3 of Candida albicans mediates iron acquisition from host ferritin. PLoS Pathogens. 2008; 4:e1000217. [PubMed: 19023418]

Alteri CJ, Hagan EC, Sivick KE, Smith SN, Mobley HL. Mucosal immunization with iron receptor antigens protects against urinary tract infection. PLoS Pathogens. 2009; 5:e1000586. [PubMed: 19806177]

Andrews SC, Robinson AK, Rodriguez-Quinones F. Bacterial iron homeostasis. FEMS Microbiol Rev. 2003; 27:215-237. [PubMed: 12829269]

Anzaldi LL, Skaar EP. Overcoming the heme paradox: heme toxicity and tolerance in bacterial pathogens. Infection and Immunity. 2010; 78:4977-4989. [PubMed: 20679437]

Baker HM, Baker EN. A structural perspective on lactoferrin function. Biochemistry and cell biology = Biochimie et biologie cellulaire. 2012; 90:320-328. [PubMed: 22292559]

Bao G, Clifton M, Hoette TM, Mori K, Deng SX, Qiu A, Viltard M, Williams D, Paragas N, Leete T, et al. Iron traffics in circulation bound to a siderocalin (Ngal)-catechol complex. Nature Chemical Biology. 2010; 6:602-609.

Bullen, JJ.; GE. Iron and infection: molecular, physiological, and clinical aspects. 2. New York, NY: John Wiley and Sons; 1999.

Cabanes D, Dehoux P, Dussurget O, Frangeul L, Cossart P. Surface proteins and the pathogenic potential of Listeria monocytogenes. Trends Microbiol. 2002; 10:238-245. [PubMed: 11973158]

Cartwright GE, Lauritsen MA, Humphreys S, Jones PJ, Merrill IM, Wintrobe MM. The Anemia Associated With Chronic Infection. Science. 1946; 103:72-73.

Cassat JE, Skaar EP. Metal ion acquisition in Staphylococcus aureus: overcoming nutritional immunity. Seminars in Immunopathology. 2012; 34:215-235. [PubMed: 22048835]

Cescau S, Cwerman H, Létoffé S, Delepelaire P, Wandersman C, Biville F. Heme acquisition by hemophores. Biometals. 2007; 20:603-613. [PubMed: 17268821]

Chen C, Pande K, French SD, Tuch BB, Noble SM. An iron homeostasis regulatory circuit with reciprocal roles in Candida albicans commensalism and pathogenesis. Cell Host \& Microbe. 2011; 10:118-135. [PubMed: 21843869]

Cornelissen CN, Kelley M, Hobbs MM, Anderson JE, Cannon JG, Cohen MS, Sparling PF. The transferrin receptor expressed by gonococcal strain FA1090 is required for the experimental infection of human male volunteers. Molecular Microbiology. 1998; 27:611-616. [PubMed: 9489672] 
Cunnington AJ, de Souza JB, Walther M, Riley EM. Malaria impairs resistance to Salmonella through heme- and heme oxygenase-dependent dysfunctional granulocyte mobilization. Nature Medicine. 2012; 18:120-127.

Daum RS, Spellberg B. Progress toward a Staphylococcus aureus vaccine. Clinical infectious diseases: an official publication of the Infectious Diseases Society of America. 2012; 54:560-567. [PubMed: 22186773]

De Voss JJ, Rutter K, Schroeder BG, Su H, Zhu Y, Barry CE 3rd. The salicylate-derived mycobactin siderophores of Mycobacterium tuberculosis are essential for growth in macrophages. Proceedings of the National Academy of Sciences of the United States of America. 2000; 97:1252-1257. [PubMed: 10655517]

Devireddy LR, Hart DO, Goetz DH, Green MR. A mammalian siderophore synthesized by an enzyme with a bacterial homolog involved in enterobactin production. Cell. 2010; 141:1006-1017. [PubMed: 20550936]

Donovan A, Brownlie A, Zhou Y, Shepard J, Pratt SJ, Moynihan J, Paw BH, Drejer A, Barut B, Zapata A, et al. Positional cloning of zebrafish ferroportin1 identifies a conserved vertebrate iron exporter. Nature. 2000; 403:776-781. [PubMed: 10693807]

Drakesmith H, Prentice AM. Hepcidin and the iron-infection axis. Science. 2012; 338:768-772. [PubMed: 23139325]

Dryla A, Gelbmann D, von Gabain A, Nagy E. Identification of a novel iron regulated staphylococcal surface protein with haptoglobin-haemoglobin binding activity. Molecular Microbiology. 2003; 49:37-53. [PubMed: 12823809]

Flo TH, Smith KD, Sato S, Rodriguez DJ, Holmes MA, Strong RK, Akira S, Aderem A. Lipocalin 2 mediates an innate immune response to bacterial infection by sequestrating iron. Nature. 2004; 432:917-921. [PubMed: 15531878]

Foster LA. Utilization and cell-surface binding of hemin by Histoplasma capsulatum. Canadian Journal of Microbiology. 2002; 48:437-442. [PubMed: 12109883]

Friedman DB, Stauff DL, Pishchany G, Whitwell CW, Torres VJ, Skaar EP. Staphylococcus aureus redirects central metabolism to increase iron availability. PLoS Pathogens. 2006; 2:e87. [PubMed: 16933993]

Gozzelino R, Andrade BB, Larsen R, Luz NF, Vanoaica L, Seixas E, Coutinho A, Cardoso S, Rebelo $\mathrm{S}$, Poli M, et al. Metabolic adaptation to tissue iron overload confers tolerance to malaria. Cell Host \& Microbe. 2012; 12:693-704. [PubMed: 23159058]

Grigg JC, Vermeiren CL, Heinrichs DE, Murphy ME. Heme coordination by Staphylococcus aureus IsdE. The Journal of Biological Chemistry. 2007; 282:28815-28822. [PubMed: 17666394]

Haley KP, Janson EM, Heilbronner S, Foster TJ, Skaar EP. Staphylococcus lugdunensis IsdG liberates iron from host heme. Journal of Bacteriology. 2011; 193:4749-4757. [PubMed: 21764939]

Halsey TA, Vazquez-Torres A, Gravdahl DJ, Fang FC, Libby SJ. The ferritin-like Dps protein is required for Salmonella enterica serovar Typhimurium oxidative stress resistance and virulence. Infection and Immunity. 2004; 72:1155-1158. [PubMed: 14742565]

Hammer ND, Skaar EP. Molecular mechanisms of Staphylococcus aureus iron acquisition. Annual Review of Microbiology. 2011; 65:129-147.

Hanscheid T, Egan TJ, Grobusch MP. Haemozoin: from melatonin pigment to drug target, diagnostic tool, and immune modulator. The Lancet Infectious Diseases. 2007; 7:675-685. [PubMed: 17897610]

Howard DH. Acquisition, transport, and storage of iron by pathogenic fungi. Clinical Microbiology Reviews. 1999; 12:394-404. [PubMed: 10398672]

Hu G, Caza M, Cadieux B, Chan V, Liu V, Kronstad J. Cryptococcus neoformans requires the ESCRT protein Vps23 for iron acquisition from heme, for capsule formation, and for virulence. Infection and Immunity. 2013; 81:292-302. [PubMed: 23132495]

Jabado N, Jankowski A, Dougaparsad S, Picard V, Grinstein S, Gros P. Natural resistance to intracellular infections: natural resistance-associated macrophage protein 1 (Nramp1) functions as a pH-dependent manganese transporter at the phagosomal membrane. The Journal of Experimental Medicine. 2000; 192:1237-1248. [PubMed: 11067873] 
Kim CM, Park YJ, Shin SH. A widespread deferoxamine-mediated iron-uptake system in Vibrio vulnificus. The Journal of Infectious Diseases. 2007; 196:1537-1545. [PubMed: 18008234]

Kirienko NV, Kirienko DR, Larkins-Ford J, Wählby C, Ruvkun G, Ausubel FM. Pseudomonas aeruginosa Disrupts Caenorhabditis elegans Iron Homeostasis, Causing a Hypoxic Response and Death. Cell Host Microbe. 2013; 13:406-416. [PubMed: 23601103]

Krause A, Neitz S, Magert HJ, Schulz A, Forssmann WG, Schulz-Knappe P, Adermann K. LEAP-1, a novel highly disulfide-bonded human peptide, exhibits antimicrobial activity. FEBS Letters. 2000; 480:147-150. [PubMed: 11034317]

Lechardeur D, Cesselin B, Liebl U, Vos MH, Fernandez A, Brun C, Gruss A, Gaudu P. Discovery of intracellular heme-binding protein HrtR, which controls heme efflux by the conserved HrtB-HrtA transporter in Lactococcus lactis. The Journal of Biological Chemistry. 2012; 287:4752-4758. [PubMed: 22084241]

Letoffe S, Redeker V, Wandersman C. Isolation and characterization of an extracellular haem-binding protein from Pseudomonas aeruginosa that shares function and sequence similarities with the Serratia marcescens HasA haemophore. Molecular Microbiology. 1998; 28:1223-1234. [PubMed: 9680211]

Long, SS.; Pickering, LK.; Prober, CG. Principles and practice of pediatric infectious diseases. 2. New York: Churchill Livingstone; 2003.

Luo M, Fadeev EA, Groves JT. Mycobactin-mediated iron acquisition within macrophages. Nature Chemical Biology. 2005; 1:149-153.

Madigan CA, Cheng TY, Layre E, Young DC, McConnell MJ, Debono CA, Murry JP, Wei JR, Barry CE 3rd, Rodriguez GM, et al. Lipidomic discovery of deoxysiderophores reveals a revised mycobactin biosynthesis pathway in Mycobacterium tuberculosis. Proceedings of the National Academy of Sciences of the United States of America. 2012; 109:1257-1262. [PubMed: 22232695]

Maresso AW, Garufi G, Schneewind O. Bacillus anthracis secretes proteins that mediate heme acquisition from hemoglobin. PLoS Pathogens. 2008; 4:e1000132. [PubMed: 18725935]

Masson PL, Heremans JF, Schonne E. Lactoferrin, an iron-binding protein in neutrophilic leukocytes. The Journal of Experimental Medicine. 1969; 130:643-658. [PubMed: 4979954]

Mazmanian SK, Skaar EP, Gaspar AH, Humayun M, Gornicki P, Jelenska J, Joachmiak A, Missiakas DM, Schneewind O. Passage of heme-iron across the envelope of Staphylococcus aureus. Science. 2003; 299:906-909. [PubMed: 12574635]

Mazmanian SK, Ton-That H, Su K, Schneewind O. An iron-regulated sortase anchors a class of surface protein during Staphylococcus aureus pathogenesis. Proceedings of the National Academy of Sciences U S A. 2002; 99:2293-2298.

McKie AT, Marciani P, Rolfs A, Brennan K, Wehr K, Barrow D, Miret S, Bomford A, Peters TJ, Farzaneh F, et al. A novel duodenal iron-regulated transporter, IREG1, implicated in the basolateral transfer of iron to the circulation. Molecular Cell. 2000; 5:299-309. [PubMed: 10882071]

McPherson CJ, Aschenbrenner LM, Lacey BM, Fahnoe KC, Lemmon MM, Finegan SM, Tadakamalla B, O’Donnell JP, Mueller JP, Tomaras AP. Clinically relevant Gram-negative resistance mechanisms have no effect on the efficacy of MC-1, a novel siderophore-conjugated monocarbam. Antimicrobial Agents and Chemotherapy. 2012; 56:6334-6342. [PubMed: 23027195]

Nairz M, Schroll A, Sonnweber T, Weiss G. The struggle for iron - a metal at the host-pathogen interface. Cellular Microbiology. 2010; 12:1691-1702. [PubMed: 20964797]

Nathan, DG.; Oski, FA.; Ginsburg, D.; Orkin, SH.; Look, AT. Nathan and Oski's hematology of infancy and childhood. 6. Philadelphia, Pa: Saunders; 2003.

Nemeth E, Tuttle MS, Powelson J, Vaughn MB, Donovan A, Ward DM, Ganz T, Kaplan J. Hepcidin regulates cellular iron efflux by binding to ferroportin and inducing its internalization. Science. 2004; 306:2090-2093. [PubMed: 15514116]

Nevitt T. War-Fe-re: iron at the core of fungal virulence and host immunity. Biometals: an international journal on the role of metal ions in biology, biochemistry, and medicine. 2011; 24:547-558. 
Noinaj N, Easley NC, Oke M, Mizuno N, Gumbart J, Boura E, Steere AN, Zak O, Aisen P, Tajkhorshid E, et al. Structural basis for iron piracy by pathogenic Neisseria. Nature. 2012; 483:53-58. [PubMed: 22327295]

Olakanmi O, Britigan BE, Schlesinger LS. Gallium disrupts iron metabolism of mycobacteria residing within human macrophages. Infection and Immunity. 2000; 68:5619-5627. [PubMed: 10992462]

Olakanmi O, Schlesinger LS, Ahmed A, Britigan BE. Intraphagosomal Mycobacterium tuberculosis acquires iron from both extracellular transferrin and intracellular iron pools. Impact of interferongamma and hemochromatosis. The Journal of Biological cChemistry. 2002; 277:49727-49734.

Pandey R, Rodriguez GM. A ferritin mutant of Mycobacterium tuberculosis is highly susceptible to killing by antibiotics and is unable to establish a chronic infection in mice. Infection and Immunity. 2012; 80:3650-3659. [PubMed: 22802345]

Park CH, Valore EV, Waring AJ, Ganz T. Hepcidin, a urinary antimicrobial peptide synthesized in the liver. Journal of Biological Chemistry. 2001; 276:7806-7810. [PubMed: 11113131]

Pearson MS, Bethony JM, Pickering DA, de Oliveira LM, Jariwala A, Santiago H, Miles AP, Zhan B, Jiang D, Ranjit N, et al. An enzymatically inactivated hemoglobinase from Necator americanus induces neutralizing antibodies against multiple hookworm species and protects dogs against heterologous hookworm infection. FASEB journal: official publication of the Federation of American Societies for Experimental Biology. 2009; 23:3007-3019. [PubMed: 19380510]

Peyssonnaux C, Zinkernagel AS, Datta V, Lauth X, Johnson RS, Nizet V. TLR4-dependent hepcidin expression by myeloid cells in response to bacterial pathogens. Blood. 2006; 107:3727-3732. [PubMed: 16391018]

Pishchany G, McCoy AL, Torres VJ, Krause JC, Crowe JE Jr, Fabry ME, Skaar EP. Specificity for human hemoglobin enhances Staphylococcus aureus infection. Cell Host Microbe. 2010; 8:544 550. [PubMed: 21147468]

Posey JE, Gherardini FC. Lack of a role for iron in the Lyme disease pathogen. Science. 2000; 288:1651-1653. [PubMed: 10834845]

Pramanik A, Stroeher UH, Krejci J, Standish AJ, Bohn E, Paton JC, Autenrieth IB, Braun V. Albomycin is an effective antibiotic, as exemplified with Yersinia enterocolitica and Streptococcus pneumoniae. International Journal of Medical Microbiology: IJMM. 2007; 297:459-469. [PubMed: 17459767]

Raffatellu M, George MD, Akiyama Y, Hornsby MJ, Nuccio SP, Paixao TA, Butler BP, Chu H, Santos RL, Berger T, et al. Lipocalin-2 resistance confers an advantage to Salmonella enterica serotype Typhimurium for growth and survival in the inflamed intestine. Cell Host \& Microbe. 2009; 5:476-486. [PubMed: 19454351]

Ratledge C, Brown KA. Inhibition of mycobactin formation in Mycobacterium smegmatis by paminosalicylate. A new proposal for the mode of action of p-aminosalicylate. The American review of respiratory disease. 1972; 106:774-776. [PubMed: 5078877]

Reniere ML, Skaar EP. Staphylococcus aureus haem oxygenases are differentially regulated by iron and haem. Molecular Microbiology. 2008; 69:1304-1315. [PubMed: 18643935]

Reniere ML, Ukpabi GN, Harry SR, Stec DF, Krull R, Wright DW, Bachmann BO, Murphy ME, Skaar EP. The IsdG-family of haem oxygenases degrades haem to a novel chromophore. Molecular Microbiology. 2010; 75:1529-1538. [PubMed: 20180905]

Schrettl M, Bignell E, Kragl C, Sabiha Y, Loss O, Eisendle M, Wallner A, Arst HN Jr, Haynes K, Haas H. Distinct roles for intra- and extracellular siderophores during Aspergillus fumigatus infection. PLoS Pathogens. 2007; 3:1195-1207. [PubMed: 17845073]

Schrettl M, Haas H. Iron homeostasis--Achilles' heel of Aspergillus fumigatus? Current Opinion in Microbiology. 2011; 14:400-405. [PubMed: 21724450]

Schryvers AB, Morris LJ. Identification and characterization of the transferrin receptor from Neisseria meningitidis. Molecular Microbiology. 1988; 2:281-288. [PubMed: 3132585]

Seixas E, Gozzelino R, Chora A, Ferreira A, Silva G, Larsen R, Rebelo S, Penido C, Smith NR, Coutinho A, et al. Heme oxygenase-1 affords protection against noncerebral forms of severe malaria. Proceedings of the National Academy of Sciences of the United States of America. 2009; 106:15837-15842. [PubMed: 19706490] 
Shio MT, Kassa FA, Bellemare MJ, Olivier M. Innate inflammatory response to the malarial pigment hemozoin. Microbes and Infection. 2010; 12:889-899. [PubMed: 20637890]

Skaar EP, Gaspar AH, Schneewind O. IsdG and IsdI, heme-degrading enzymes in the cytoplasm of Staphylococcus aureus. The Journal of Biological Chemistry. 2004a; 279:436-443. [PubMed: 14570922]

Skaar EP, Gaspar AH, Schneewind O. Bacillus anthracis IsdG, a heme-degrading monooxygenase. Journal of Bacteriology. 2006; 188:1071-1080. [PubMed: 16428411]

Skaar EP, Humayun M, Bae T, DeBord KL, Schneewind O. Iron-source preference of Staphylococcus aureus infections. Science. 2004b; 305:1626-1628. [PubMed: 15361626]

Stauff DL, Bagaley D, Torres VJ, Joyce R, Anderson KL, Kuechenmeister L, Dunman PM, Skaar EP. Staphylococcus aureus HrtA is an ATPase required for protection against heme toxicity and prevention of a transcriptional heme stress response. Journal of Bacteriology. 2008; 190:35883596. [PubMed: 18326576]

Stauff DL, Torres VJ, Skaar EP. Signaling and DNA-binding Activities of the Staphylococcus aureus HssR-HssS Two-component System Required for Heme Sensing. Journal of Biological Chemistry. 2007; 282:26111-26121. [PubMed: 17635909]

Stranger-Jones YK, Bae T, Schneewind O. Vaccine assembly from surface proteins of Staphylococcus aureus. Proceedings of the National Academy of Sciences of the United States of America. 2006; 103:16942-16947. [PubMed: 17075065]

Tong Y, Guo M. Bacterial heme-transport proteins and their heme-coordination modes. Archives of Biochemistry and Biophysics. 2009; 481:1-15. [PubMed: 18977196]

Torres VJ, Pishchany G, Humayun M, Schneewind O, Skaar EP. Staphylococcus IsdB is a hemoglobin receptor required for hemeaureus iron utilization. Journal of Bacteriology. 2006; 188:8421-8429. [PubMed: 17041042]

Torres VJ, Stauff DL, Pishchany G, Bezbradica JS, Gordy LE, Iturregui J, Anderson KL, Dunman PM, Joyce S, Skaar EP. A Staphylococcus aureus regulatory system that responds to host heme and modulates virulence. Cell Host Microbe. 2007; 1:109-119. [PubMed: 18005689]

Tullius MV, Harmston CA, Owens CP, Chim N, Morse RP, McMath LM, Iniguez A, Kimmey JM, Sawaya MR, Whitelegge JP, et al. Discovery and characterization of a unique mycobacterial heme acquisition system. Proceedings of the National Academy of Sciences of the United States of America. 2011; 108:5051-5056. [PubMed: 21383189]

van Crevel R, Parwati I, Sahiratmadja E, Marzuki S, Ottenhoff TH, Netea MG, van der Ven A, Nelwan RH, van der Meer JW, Alisjahbana B, et al. Infection with Mycobacterium tuberculosis Beijing genotype strains is associated with polymorphisms in SLC11A1/NRAMP1 in Indonesian patients with tuberculosis. The Journal of Infectious Diseases. 2009; 200:1671-1674. [PubMed: 19863441]

Van Zandt KE, Sow FB, Florence WC, Zwilling BS, Satoskar AR, Schlesinger LS, Lafuse WP. The iron export protein ferroportin 1 is differentially expressed in mouse macrophage populations and is present in the mycobacterial-containing phagosome. Journal of Leukococyte Biology. 2008; 84:689-700.

Velayudhan J, Castor M, Richardson A, Main-Hester KL, Fang FC. The role of ferritins in the physiology of Salmonella enterica sv. Typhimurium: a unique role for ferritin B in iron-sulphur cluster repair and virulence. Molecular Microbiology. 2007; 63:1495-1507. [PubMed: 17302823]

Vidal S, Tremblay ML, Govoni G, Gauthier S, Sebastiani G, Malo D, Skamene E, Olivier M, Jothy S, Gros P. The Ity/Lsh/Bcg locus: natural resistance to infection with intracellular parasites is abrogated by disruption of the Nramp1 gene. The Journal of Experimental Medicine. 1995; 182:655-666. [PubMed: 7650477]

Wakeman CA, Hammer ND, Stauff DL, Attia AS, Anzaldi LL, Dikalov SI, Calcutt MW, Skaar EP. Menaquinone biosynthesis potentiates haem toxicity in Staphylococcus aureus. Molecular Microbiology. 2012; 86:1376-1392. [PubMed: 23043465]

Weiss G. Modification of iron regulation by the inflammatory response. Best practice $\&$ research Clinical haematology. 2005; 18:183-201. [PubMed: 15737884] 
Weissman Z, Shemer R, Conibear E, Kornitzer D. An endocytic mechanism for haemoglobin-iron acquisition in Candida albicans. Molecular Microbiology. 2008; 69:201-217. [PubMed: 18466294]

Weissman Z, Shemer R, Kornitzer D. Deletion of the copper transporter CaCCC2 reveals two distinct pathways for iron acquisition in Candida albicans. Molecular Microbiology. 2002; 44:1551-1560. [PubMed: 12067343]

Williamson AL, Lecchi P, Turk BE, Choe Y, Hotez PJ, McKerrow JH, Cantley LC, Sajid M, Craik CS, Loukas A. A multi-enzyme cascade of hemoglobin proteolysis in the intestine of bloodfeeding hookworms. The Journal of Biological Chemistry. 2004; 279:35950-35957. [PubMed: 15199048]

Zapotoczna M, Heilbronner S, Speziale P, Foster TJ. Iron-regulated surface determinant (Isd) proteins of Staphylococcus lugdunensis. Journal of Bacteriology. 2012; 194:6453-6467. [PubMed: 23002220]

Zhao H, Konishi A, Fujita Y, Yagi M, Ohata K, Aoshi T, Itagaki S, Sato S, Narita H, Abdelgelil NH, et al. Lipocalin 2 bolsters innate and adaptive immune responses to blood-stage malaria infection by reinforcing host iron metabolism. Cell Host \& Microbe. 2012; 12:705-716. [PubMed: 23159059]

Zwilling BS, Kuhn DE, Wikoff L, Brown D, Lafuse W. Role of iron in Nramp1-mediated inhibition of mycobacterial growth. Infection and Immunity. 1999; 67:1386-1392. [PubMed: 10024586] 
A

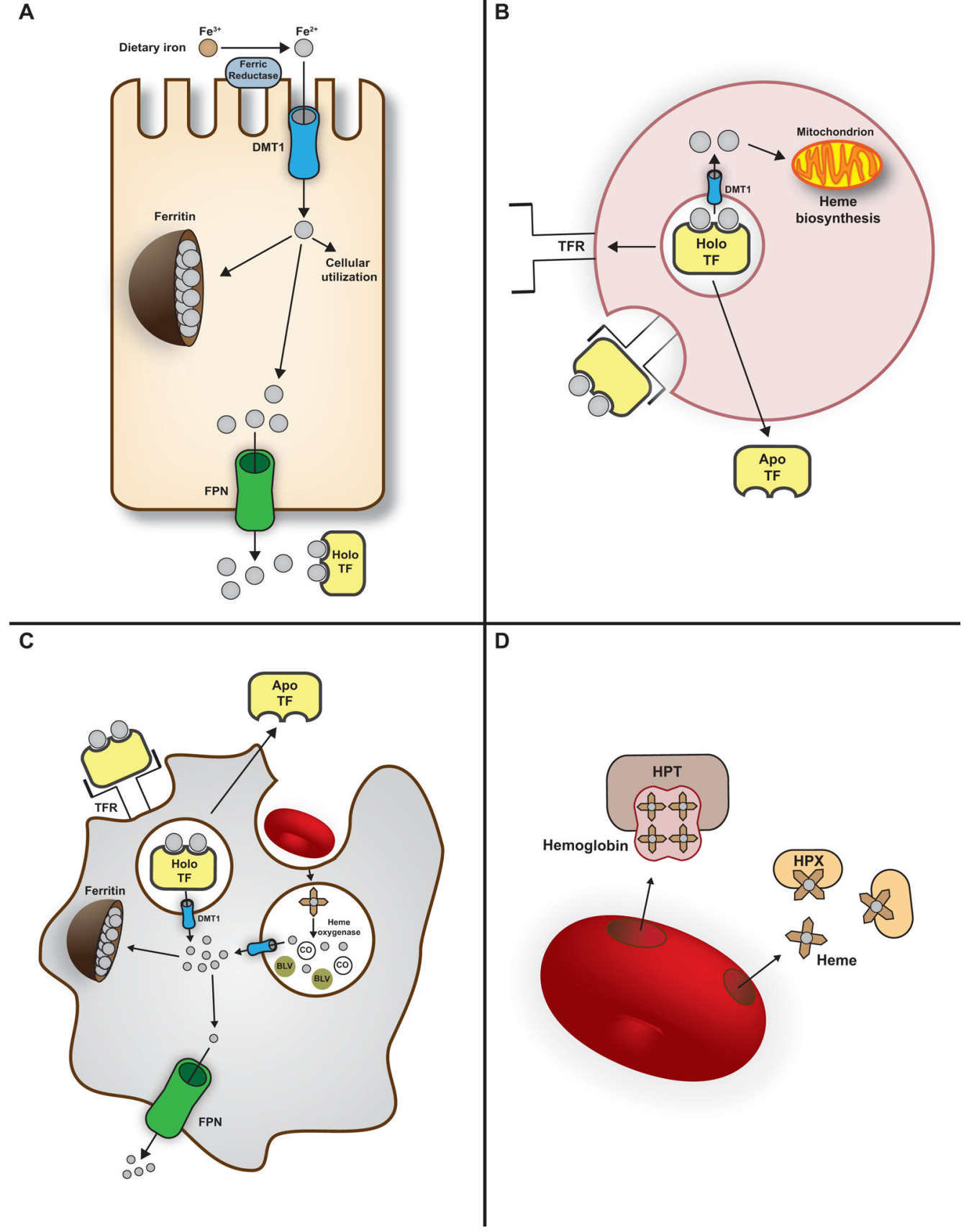

Figure 1. Human iron homeostasis

A) Prior to transport into duodenal enterocytes, dietary ferric iron is reduced by ferric reductases present in the apical brush border. Ferrous iron is transported into the cell by DMT1, after which it can be used for cellular processes, stored in ferritin, or exit the cell via ferroportin (FPN). Extracellular iron is bound with high affinity by transferrin (TF). B) Erythroid precursors acquire iron via transferrin receptor (TFR) - mediated endocytosis of holo-TF, and iron is then transported into the cytoplasm by DMT1. Cytoplasmic iron can subsequently be shuttled to mitochondria for use in heme biosynthesis. C) Macrophages acquire iron via TFR-mediated endocytosis of holo-TF or recycling of senescent erythrocytes. Heme oxygenases catalyze the degradation of heme to iron, $\mathrm{CO}$, and 
biliverdin, after which iron is transported to the cytoplasm by DMT1. Cytoplasmic iron can be used for cellular processes, stored in ferritin, or transported out of the macrophage by FPN. D) Hemoglobin or heme released upon erythrocyte lysis is avidly scavenged by haptoglobin (HPT) or hemopexin (HPX), respectively. 
A

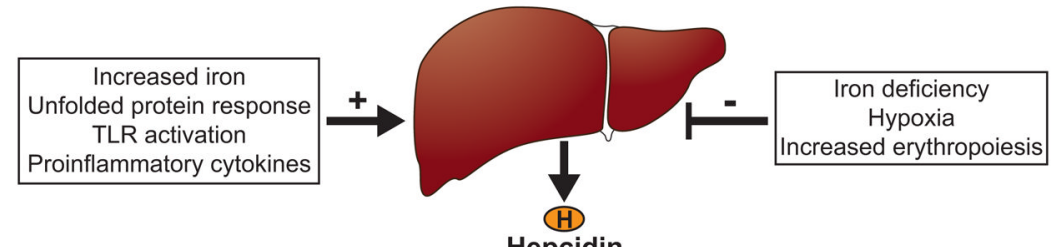

Hepcidin

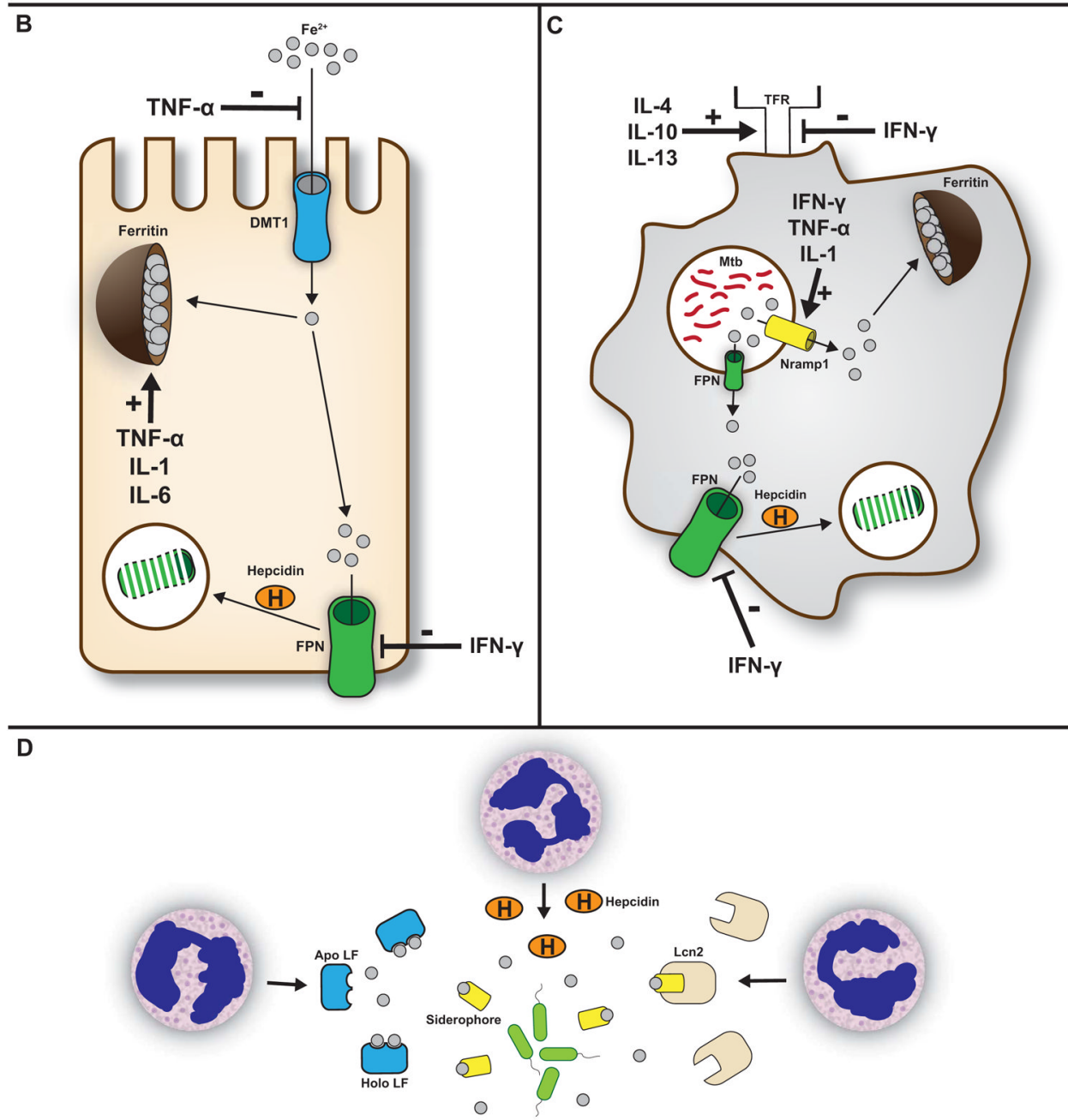

Figure 2. Iron limitation as an innate immune defense

A) Regulation of hepcidin synthesis during infection and inflammation. B) Proinflammatory cytokines fortify iron-withholding defenses via repression of DMT1-mediated iron absorption and activation of ferritin synthesis. Hepcidin induces the internalization and degradation of FPN, further limiting iron egress. C) In response to inflammatory signals, macrophages downregulate the TFR, limiting iron uptake. Iron is actively removed from the phagosome via Nramp1, an activity stimulated by IFN- $\gamma$, TNF- $a$, and IL- 1 . These actions culminate in reduced iron availability to intracellular pathogens such as Mtb (depicted in red). D) Innate immune effectors further limit iron availability at the infectious focus through local production of lactoferrin (LF), hepcidin, and siderocalin/lipocalin-2 (Lcn2). Pathogens (depicted in green) circumvent iron sequestration through the production of siderophores. 


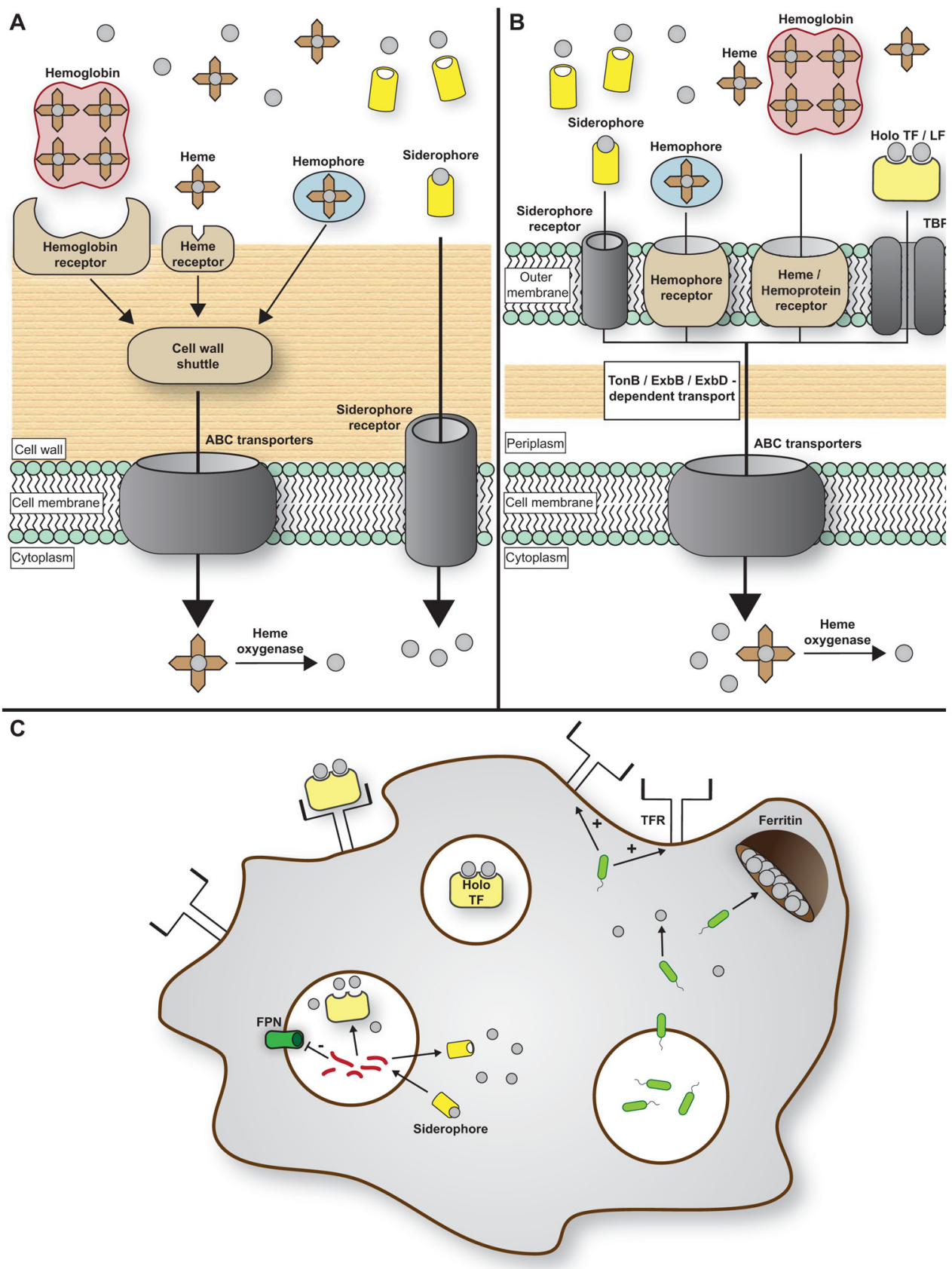

Figure 3. Bacterial strategies for iron acquisition

Bacterial pathogens use a variety of strategies to overcome host iron limitation. Not shown are ferric/ferrous iron transporters and the Borrelia strategy of manganese substitution in metalloenzymes. A) Gram-positive organisms can obtain iron through the use of heme and hemoprotein cell surface receptors, or through secretion of hemophores (B. anthracis). Heme is then shuttled across the cell wall prior to transport into the cytoplasm by ABC-type transporters. Once in the cytoplasm, heme can be degraded by heme oxygenases to release iron. Alternatively, Gram-positive pathogens may secrete siderophores, which capture iron and then re-enter the cell through the use of specific transporters. B) Gram-negative organisms also utilize siderophores and heme/hemoprotein receptors to obtain host iron. 
Select Gram-negative pathogens express transferrin (TF) or lactoferrin (LF) binding proteins (TBP/LBP) that allow for use of transferrin- or lactoferrin-bound iron. Gram-negative bacteria require energy generated from the TonB/ExbB/ExbD system to enable transport across the outer membrane and periplasm, prior to delivery into the cytoplasm by ABC-type transporters. C) Intracellular pathogens also produce siderophores, which in the case of Mtb (depicted in red) can diffuse out of the phagosome to capture cytoplasmic iron. Additionally, Mtb and other intracellular pathogens can acquire iron from TF as it cycles through the endocytic pathway. Other intracellular pathogens (depicted in green) escape from the phagosome, allowing use of free cytoplasmic iron and ferritin-iron as a nutrient source. Intracellular pathogens may also manipulate host cell iron homeostasis to increase iron availability. For example, Mtb inhibits expression of FPN, effectively increasing intraphagosomal iron content. Furthermore, some intracellular pathogens enhance expression of the transferrin receptor (TFR). 